\title{
Persistence to continuous punishment and nonreward following training with intermittent punishment and nonreward
}

\author{
R. K. BANKS 1 \\ UNIVERSITY OF WATERLOO
}

Intermittent punishment of an instrumental response in rats increased persistence to continuous punishment when all punishment administrations were coupled with nonreward. The results were seen as consistent with a conditioning-model theory of the effect of intermittent punishment.

In a recent experiment (Banks, 1966) it was found that the intermittent punishment of an instrumental approach response increased its persistence to continuous punishment. Two groups of rats were trained to run a straight alley for food. The Ss in one group were shocked $30 \%$ of the time they took food, while $\mathrm{Ss}$ in the other group received the same number of shocks in a different situation (to control for possible adaptation to shock). When tested under continuous punishment (CP) conditions Ss who had received intermittent punishment (IP) training persisted longer than Ss who had received only control shocks (for convenience in the present paper the finding of increased persistence to CP following IP training is termed an intermittent punishment effect IPE).

The results were interpreted by extending Amsel's (1962) conditioning-model theory of the role of nonreward in the partial reinforcement effect to the effect of punishment. It was argued that during IP training a classically conditioned anticipatory punishment response $\left(r_{p}\right)$ and its proprioceptive stimulation ( $\left.s_{p}\right)$ developed to stimuli in the goal region and through stimulus generalization and higher order conditioning was elicited by stimuli antedating the goal. Since $s_{p}$ is aversive, it initially elicited avoidance tendencies which interfered with approach to the goal. However, as the approach response continued to be made and reinforced in the presence of $s_{p}$, an association formed between $s_{p}$ and the approach response and $s_{p}$ came to elicit approach rather than avoidance tendencies. When CP began, $s_{p}$ occurred for all Ss and elicited approach tendencies in IP Ss, but only avoidance tendencies in control Ss.

In this demonstration of IPE all punishment administrations were paired with reward. Shock typically occurred just after contact with food and preceded food consumption. In a recent experiment Melvin \& Brown (1964) found that the aversiveness of a light stimulus was reduced if food was presented just after the light. It might be suggested that IPE was due to a somewhat similar effect through which the aversiveness of shock was reduced by its pairing with food during IP training. One purpose of the present experiment was to determine whether IPE was due to such an effectby testing for the occurrence of IPE when all punishment administrations were paired with nonreward.

A second purpose of the experiment was to investigate the possibility that shocks administered to control Ss, rather than habituating them to shock, actually had a sensitizing effect so that shocks during CP were more aversive than for IP Ss. This possibility was tested by including two control groups, one shocked in a different situation, as in the first experiment, and the other receiving no shocks until the onset of CP.

Subjects

Twenty-seven male albino rats, averaging $220 \mathrm{gm}$ at the beginning of the experiment, served as Ss.

Apparatus

A straight black runway, $5 \mathrm{ft}$.long, $5 \mathrm{in}$. wide and 6 in. high, with a grid floor, was used as apparatus. The first 7 in. and the last 11 in. were separated from the remaining portion by guillotine doors and served as start and goal boxes respectively. A wooden food cup was placed on the grid near the goal-box wall. The cup was sufficiently deep that a food pellet in the cup was not visible until Swas at the cup. Raising the start door activated a recording timer which was stopped when $S$ broke a photo beam placed 2 in. in front of the food cup. A second piece of apparatus was a plywood box with a $7 \mathrm{x}$ $8 \mathrm{in}$. grid floor and $12 \mathrm{in.} \mathrm{sides,} \mathrm{painted} \mathrm{black} \mathrm{throughout.}$ The grid floors of both the plywood box and the runway were connected to a shock generator.

\section{Procedure}

Experimental sessions were begun following $24 \mathrm{hr}$. food deprivation and continued at $6 \mathrm{hr}$. intervals throughout the study. Water was ad lib, but food consumption was restricted to the $.045 \mathrm{gm}$ Noyes pellets placed in the goal box throughout the experiment. During the first five sessions Ss were handled and placed individually in the runway with free access to food pellets placed on a wooden tray near the food cup for about $15 \mathrm{~min}$. The next five sessions consisted of 10 trials each, to one food pellet per trial (the minimum intertrial interval was 6 min. and this was maintained throughout the experiment). The Ss were then assigned to three groups, an intermittent punishment group (IP), a shocked control group (SC), and a nonshocked control group (NC), matched on the basis of response latencies over the first five sessions. A further eight sessions, of 10 trials each, were then carried out.

The Ss in the IP group were shocked on three trials in each session (randomly selected for each $\mathrm{S}$, for each 
session, with the restriction that no more than two shocks could be consecutive). No food was placed in the food cup on these trials and breaking the photobeam in front of the cup activated a $2.0 \mathrm{sec}$. delay timer which energized the shock generator delivering a $.32 \mathrm{ma}$ shock to the grid floor of the goal box for $.1 \mathrm{sec}$. The Ss in the SC group received nonreward on the same trials as their matched $S$ in the IP group, but were never shocked in the goal box at this time. About $1 \mathrm{~min}$. after they had received their nonreward trial they were removed from their home cage, placed in the plywood box and given a shock of the same duration and intensity as that administered to the IP S. The Ss in the NC group also received nonreward on the same trial as the experimental match, but were never shocked during these eight sessions.

If $\mathbf{S}$ failed to break the photo beam in the goal box within $120 \mathrm{sec}$. of the raising of the start door, his latency was recorded as $120 \mathrm{sec}$. and he was removed from the apparatus. Food consumption and shock administrations were kept constant by placing $S$ in the goal box about $1 \mathrm{~min}$. later and leaving him the re until he took the food pellet, or broke the photo beam. Following these eight sessions all Ss received two sessions, of 10 trials each, in which punishment, coupled with nonreward, was administered on every trial.

Results and Discussion

During the eight sessions prior to CP the IP group showed an initial increase in latency and a subsequent decrease while the control groups continued to perform at their previous baseline. By the first CP trial the IP group was performing with a mean latency of $5.4 \mathrm{sec}$. compared to $1.1 \mathrm{sec}$. for both the SC and NC groups. Over the $20 \mathrm{CP}$ trials the IP group performed with a mean latency of $39.2 \mathrm{sec}$. compared to 94.4 for the SC group and 103.1 for the NC group. Individual t-tests of the difference in latency during CP indicated a significant difference between the IP and $S C$ groups $(t=3.63, d f=8$, $p<.01)$ and between the IP and NC groups $(t=5.03$, $\mathrm{df}=8, \mathrm{p}<.001$ ). The difference between the two control groups was of borderline significance $(t=1.97, d f=8$, p $>.05<.10$ )。

The greater persistence shown by IP Ss than by controls indicates that IPE does not depend on the coupling of punishment with reward. As such the results are consistent with a conditioning-model theory of IPE empha- sizing the development of $r_{p}-s_{p}$ and the association between $s_{p}$ and approach tendencies and argue against an interpretation of IPE in terms of shock losing its aversiveness through association with reward.

The fact that the shocked controls tended to be more persistent than nonshocked controls suggests that control shock may have produced some habituation to shock in these Ss. This difference is also open to a stimulustrace interpretation (Sheffield, 1949). It could be argued that because shocked controls received training trials shortly before being shocked (a minimum of $5 \mathrm{~min}$.) they acquired an association between stimulus traces of shock and the instrumental response. Thus when $C P$ began and traces of shock were present on all trials these Ss tended to persist because of the association between shock traces and approach tendencies.

While the stimulus-trace interpretation may be appropriate for the differences between the control groups, it is of doubtful value in accounting for the difference between the IP group and the shocked control group. Both groups had the same number of rewarded trials following shock administrations. They differed in that controls were shocked $5 \mathrm{~min}$. (minimum) before the onset of the next trial, while intermittently punished Ss were shocked $6 \mathrm{~min}$. (minimum) before the next trial. If a stimulustrace interpretation attributes the slight difference between shocked and nonshocked controls to the presence or absence of shock traces during training, it seems inappropriate to attribute the marked difference between IP Ss and shocked controls to small differences in magnitude of shock traces during training.

\section{References}

Amsel, A. Frustrative nonreward in partial reinforcement and discrimination learning: Some recent history and a theoretical extension. Psychol. Rev., 1962, 69, 306-328.

Banks, R. K. Persistence to continuous punishment following intermittent punishment training. J. exp. Psychol., 1966, 71 , 373-377.

Melvin, K. B., \& Brown, J. S. Neutralization of an aversive light stimulus as a function of number of paired presentations with food. J. comp. physiol. Psychol, 1964, 58, 350-353.

Sheffield, V. F. Extinction as a function of partial reinforcement and distribution of practice. $J$. exp. Psychol., 1949, 39, 511-526. Note

1. This research was supported by a grant from the National Re search Council of Canada. 